\title{
PAISAGEM E ESTRATÉGIAS NA PATRIMONIALIZAÇÃO DA CULTURA MATERIAL E DA NATUREZA NA SERRA DA CAPIVARA-PI
}

\section{LANDSCAPE AND STRATEGIES IN THE PATRIMONIALIZATION OF THE MATERIAL CULTURE AND NATURE IN SERRA DA CAPIVARA-PI}

\author{
Diva Maria Freire Figueiredo \\ Myriam Bahia Lopes
}

\begin{abstract}
Resumo
Este artigo percorre os campos do patrimônio cultural, proteção do meio ambiente e arqueologia para tratar a paisagem e os sítios arqueológicos e compreender suas concepções e práticas, tendo como estudo de caso a patrimonialização da Serra da Capivara. Em uma abordagem mais ampla, destacamos os significados atribuídos à paisagem nas narrativas patrimoniais brasileiras desde a instituição da preservação do patrimônio. Em uma abordagem restrita ao tema, estudamos as narrativas usadas na proteção e na gestão da Serra da Capivara. Revisão bibliográfica e análise das narrativas patrimoniais em documentos públicos, ancoradas em noção polissêmica de paisagem, permitem observar uma tensão entre duas perspectivas de argumentos que a justificam. Por um lado, a perspectiva que considera o homem integrado à natureza, como elemento interativo e, de outro, a perspectiva que considera o homem separado da natureza.
\end{abstract}

Palavras-chave: Paisagem. Patrimônio. Arqueologia. Natureza.

\begin{abstract}
This article approaches the fields of cultural heritage, environmental protection and archeology to discuss the landscape and the archaeological sites and understand their conceptions and practices, taking as a case study the Serra da Capivara's patrimonialization. In a broader approach, we highlight the meanings attributed to the landscape in the Brazilian heritage narratives since the institution of heritage preservation. In a restrict approach to the theme, we study the narratives used in the protection and management of Serra da Capivara. Bibliographic review and analysis of the heritage narratives in public records, anchored by polysemic notion of landscape, allow us to observe a tension between two perspectives of arguments that justify it. On the one hand, the perspective that considers man integrated with nature as an interactive element and, on the other, the perspective that considers man detached from nature.
\end{abstract}

Keyword: Landscape. Heritage. Archaeology. Nature. 


\section{INTRODUÇÃO}

O Parque Nacional da Serra da Capivara (PARNA SC) foi criado pelo Decreto $\mathrm{n}^{\circ} 85.548$, de 5 de junho de 1979 , com área de aproximadamente 129.140ha no semiárido nordestino do Piauí. Seu território abrange atualmente os municípios de São Raimundo Nonato, João Costa, Coronel José Dias e Brejo do Piauí. Faz fronteira com duas formações geológicas, a bacia sedimentar Maranhão-Piauí e a depressão periférica do rio São Francisco, com serras, planícies e vales íngremes que englobam áreas de vegetação de Caatinga, Cerrado e Mata Úmida (Figura 1). Possui mais de 1.200 sítios arqueológicos com predomínio de inscrições rupestres, em sua maioria pinturas, e quatro cavernas, com uma história de ocupação humana resultante de eventos geológicos e climáticos no Brasil e na América Latina (FREIRE et al., 2017).

Nosso objetivo geral é afirmar a importância da articulação de duas categorias do patrimônio: bem arqueológico e paisagem. As duas estão presentes no momento inicial da institucionalização da preservação do patrimônio no Brasil, em 1937, com a criação do Instituto do Patrimônio Histórico e Artístico Nacional (Iphan) e a promulgação do Decreto-lei n² 25/1937.

O interesse institucional por esses patrimônios se manifesta pela criação do Livro do Tombo Arqueológico, Etnográfico e Paisagístico e a prática da sua proteção pela inscrição neste livro. Decorridos oitenta anos, o Iphan elegeu apenas 33 bens inscritos exclusivamente pelo seu valor paisagístico e 17 bens arqueológicos, não incluídos os conjuntos urbanos associados aos valores previstos nos outros livros. Números pequenos se comparados aos bens arquitetônicos e urbanísticos inscritos nos Livros de Tombo Artístico e Histórico, prevalentes na trajetória do órgão federal.

Sobre o Livro do Tombo Arqueológico, Etnográfico e Paisagístico, o Decreto-Lei $n^{\circ} 25$ estabelece que nele sejam registradas "as coisas pertencentes às categorias de arte arqueológica, etnográfica, ameríndia e popular, e bem assim as mencionadas no $\S 2^{\circ}$ do citado art.1 ${ }^{\circ \prime}$ (BRASIL, 1937, p. 2). Equipara aos bens do artigo primeiro, enquanto objeto do tombamento, "os monumentos naturais, os sítios e paisagens de feição notável dotada

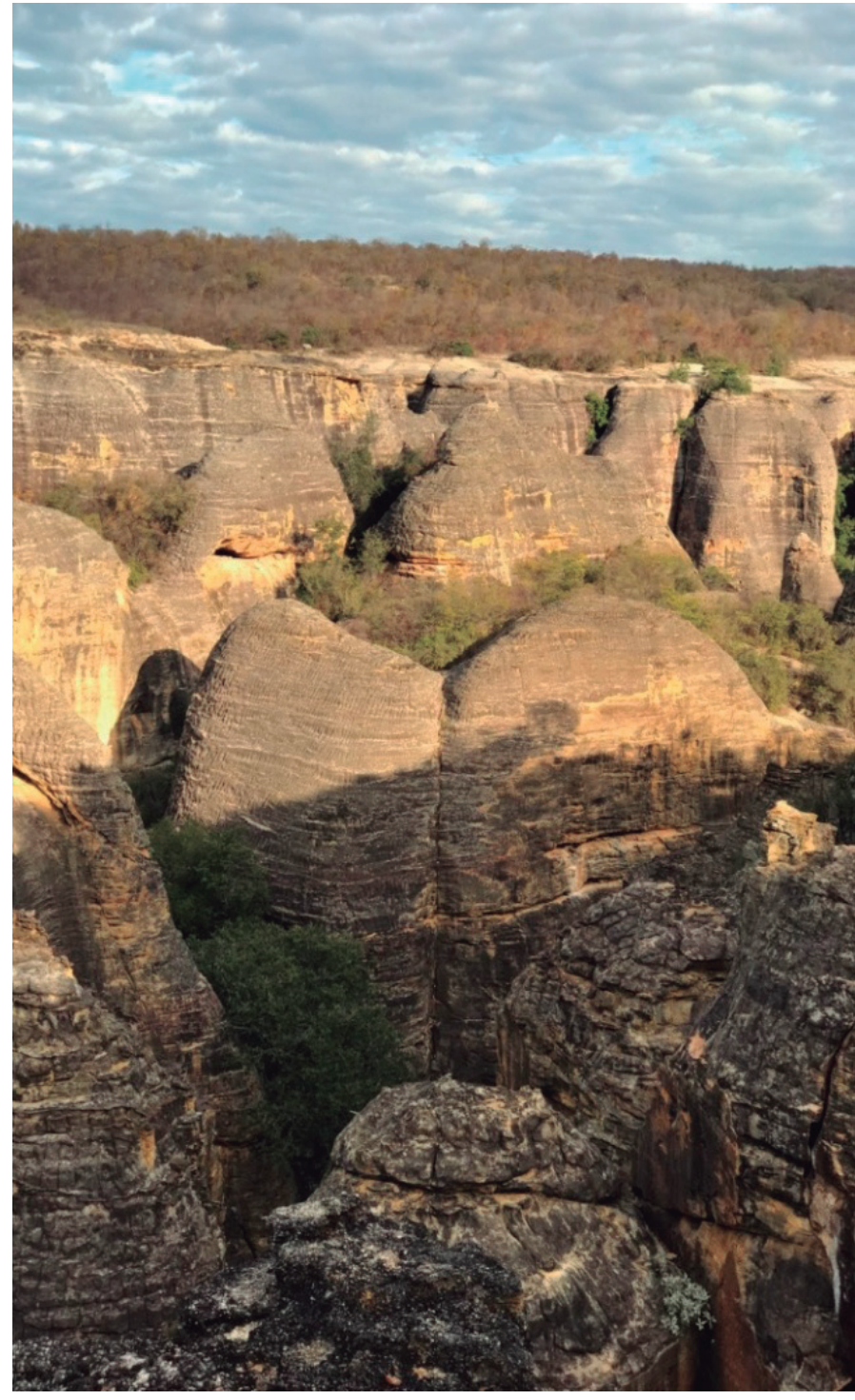

Figura 1: Vista de um dos vales do Parna SC durante a estiagem, mostrando o relevo e o contraste da vegetação entre o planalto, seca, e o fundo do vale, verde. 
pela natureza ou agenciada pelo homem". Ou seja, as paisagens naturais são acrescentadas como objetos da proteção prevista no artigo primeiro do decreto, equiparando-as às paisagens culturais, mas independentes destas. Neste sentido, diferencia-se da postura de Mário de Andrade no seu anteprojeto de lei para o patrimônio cultural, que previa o tombamento das paisagens sempre integradas à arte popular, arqueológica e ameríndia (RIBEIRO, 2007).

A abordagem destes dois patrimônios no IPHAN se faz por formas variadas. O advento da Lei $n^{\circ} 3924$, de 1961 (BRASIL, 1961), que dispõe sobre os monumentos arqueológicos e pré-históricos, parece ter preenchido a expectativa de proteção para esta categoria de bens, com menos rigor que o tombamento. O primeiro dispositivo legal e sua regulamentação posterior protegem os sítios e monumentos arqueológicos de destruição pela exploração econômica. Eles regulam as pesquisas e escavações arqueológicas nestes locais e podem admitir, para aqueles ameaçados por empreendimentos potencialmente destruidores, o resgate dos vestígios arqueológicos. A posterior liberação das áreas destes sítios aos empreendimentos é também uma possibilidade, o que poderia acarretar perdas irreparáveis para os registros rupestres.

A partir da década de 1960, destaca-se também a crescente preocupação com os valores paisagísticos dos conjuntos urbanos e rurais $^{1}$. A inscrição da Serra do Curral, em Belo Horizonte, realizada em 1962 e justificada pelos valores paisagísticos naturais, em meio à polêmica relacionada à explotação do minério de ferro, inaugurou a atenção voltada ao patrimônio natural. Mas foi na década de 1970 que ela agregou novos bens ao Livro do tombo Arqueológico, Etnográfico e Paisagístico, com a inscrição dos celebrados afloramentos rochosos e morros do Rio de Janeiro e outros mais.

1 Os valores históricos e artísticos foram preponderantes nos argumentos para o

tombamento destes bens caracterizados por conjuntos de edificações ou intervenções humanas sobre o ambiente, com sua inscrição nos respectivos Livros do Tombo Histórico e do Tombo Artístico.
A crescente preocupação ecológica mundial, manifesta durante o século XX, resulta no Brasil, com a constituição de 1988, na adoção de instrumentos de proteção da natureza e da cultura na área da política de meio ambiente. Essa política também elege a paisagem e o bem arqueológico como objetos da patrimonialização. Os vestígios ou bens arqueológicos tomados in situ são abordados dentro da própria noção integradora da paisagem, que amplia e aproxima seu domínio com a noção de meio ambiente, segundo os aportes teóricos de diversas disciplinas, como a geografia, a história e a própria arqueologia.

Neste texto, analisamos o processo de patrimonialização de ambas, cultura e natureza, colocado como o desafio do século $\mathrm{XXI}$ e permeado por ambiguidades e conflitos. O processo envolve dois campos regulados por leis, procedimentos e rituais específicos conduzidos por cientistas, intelectuais e agentes empenhados em construir referências à memória dos grupos que constituem a sociedade brasileira e conservar a natureza. A análise é feita na perspectiva do homem integrado à natureza, em contínua interação do organismo e do meio em oposição ao homem separado da natureza, numa postura antropocêntrica e utilitária (MEYER, 2008).

Segundo Meyer (2008), as concepções que separam o homem da natureza sempre a apresentam como objeto que inclui o cenário e a paisagem. Na maioria das acepções empregadas, o usufruto, extração, domínio, controle e uso dos recursos naturais não fazem parte do "conviver", revela a ruptura da interação com o mundo natural, na tentativa de distinguir o homem dos demais seres. A autora observa que a natureza é tratada nos diálogos com os vaqueiros na obra de Guimarães Rosa como sujeito e não como objeto de troca e mercadoria. Meyer ressalta o entrelaçamento entre cultura e natureza e o papel importante da literatura e da imaginação criadora para o debate ecológico.

Buscamos evidenciar a tese de que noções distintas de paisagem ancoram as narrativas patrimoniais usadas nas práticas e nos fundamentos teóricos que orientaram a condução das políticas federais do patrimônio cultural e do meio ambiente: integradas, 
numa mediação entre cultura e natureza; antagônicas e conflituosas, ora fundamentadas na cultura e ora na natureza. Para atingir este objetivo, analisamos o ambicioso tema de pesquisa interdisciplinar desenvolvido na Serra da Capivara: "O Homem no sudeste do Piauí, da Pré-História aos dias atuais. A interação Homem-Meio"2 (BAIÃO FILHO, 2013, p. 3). Há 40 anos seus idealizadores realizam pesquisas, protagonizam a proteção e continuam a participar da gestão de um amplo território do sudeste do Piauí. A atuação dos pesquisadores impactou e vem modificando a vida nesta região, substituindo com frequência o Estado ao desempenharem os papéis de agentes dos órgãos do patrimônio cultural e do meio ambiente.

\section{A Paisagem na Arqueologia}

O tema da pesquisa arqueológica desenvolvida no sudeste do Piauí sugere uma interação do homem ao meio, a qual aponta para uma aproximação com a paisagem, mencionada de forma explícita em títulos de trabalhos desenvolvidos e divulgados em meio científico (PESSIS; MARTIN; GUIDON, 2014). As inferências neste sentido demandam explorar o pensamento arqueológico sobre a paisagem numa perspectiva histórica que enfatize o recorte temporal das pesquisas realizadas na região. Assim, levantamos com mais propriedade a hipótese de uma abordagem integrada da paisagem nas pesquisas da Serra da Capivara. Podemos, ainda, estender esta hipótese à patrimonialização e à própria gestão da preservação da Serra, posta a grande participação dos arqueólogos pesquisadores na proteção e gestão do patrimônio ali existente.

O entendimento das relações entre paisagem e arqueologia sofre mudanças com o advento das escolas processual e pós-processual. Da segunda escola, Leroi-Gourhan possui grande influência nas pesquisas da Serra da Capivara, como veremos adiante. Entre as mudanças trazidas por estas escolas, destacam-se as abordagens mais amplas no objeto de estudo da arqueologia da pai-

\footnotetext{
2 Tema do projeto de pesquisa arqueológica apresentado ao IPHAN para autorização sob a coordenação da Dra. Niède Guidon na região da Serra da Capivara, em cumprimento da Lei $n^{\circ}$ 3924/1961 (BRASIL, 1961)
}

sagem. Os primeiros estudos sofrem influência da teoria dos sistemas e focam as relações entre o meio ambiente e a sociedade. Esses estudos também procuram compreender as implicações dessa teoria na economia e subsistência dos grupos humanos, a exemplo dos realizados em áreas de captação de recursos e de manejo florestal. As possibilidades de pesquisa da paisagem na arqueologia crescem com as mudanças de abordagem da disciplina (LINO, 2012).

Knapp e Ashmore (1999) observam que a preocupação dos arqueólogos com o passado humano dialoga há muito tempo com o seu interesse pelo espaço e, portanto, com as paisagens. 0 pensamento arqueológico sobre a natureza da paisagem é que mudou sensivelmente. A paisagem, numa visão minimalista, é o pano de fundo onde são traçados os vestígios arqueológicos. Dos pontos de vista econômicos e políticos, elas são fontes de recursos, refúgios e riscos que influenciam as ações e condições de vida do homem. Entretanto, as mais recentes contribuições sobre as noções de paisagem consideram seus aspectos sociais e simbólicos: "[...] a paisagem é uma entidade que existe em virtude de ser percebida, vivenciada e contextualizada pelas pessoas" (Knapp; Ashmore, 1999, p.1).

As percepções da paisagem do Parna SC pelas pessoas que lá trabalham, habitam o lugar ou apenas o visitam ou conhecem apontam para uma diversidade de visões e uma paisagem cambiante. Conhecer essas visões e confrontá-las com as políticas de proteção do patrimônio cultural e do meio ambiente visa compreender como lidamos com as mudanças da paisagem no Brasil. As práticas europeias, segundo acepções da Convenção Europeia da Paisagem (CEP), viabilizam comparações com as práticas e acepções brasileiras. A CEP, através da gestão, propõe "orientar e harmonizar as alterações resultantes dos processos sociais, econômicos e ambientais" (CONVENÇÃO..., 2005, p. 3, grifo nosso).

Knapp e Ashmore (1999) também apontam, nas várias abordagens arqueológicas da paisagem existentes, duas perspectivas antagônicas. De um lado, a paisagem é teorizada como um pano de fundo passivo, de outro, é uma entidade ativa nas complexas relações humanas. Segundo esses autores, a arqueologia, notada- 
mente a de assentamentos, atentava para o espaço e a paisagem, mas esta era vista como um pano de fundo passivo ou determinado pela cultura. Agora, a paisagem é vista como entidade ativa e complexa relativa às vidas humanas. A segunda perspectiva é uma consequência da expansão das análises interpretativas para além dos sítios isolados, envolvendo traços humanos "em e entre loci" nos chamados "lugares de interesse especial". Assim, a partir de 1992 resultam diversas perspectivas (arqueologia sem sítio, externa, distribucional) e várias abordagens da arqueologia da paisagem.

Concordamos com a reflexão dos sobrecitados arqueólogos sobre a polarização da percepção e interpretação entre natureza e cultura, que só dificulta o estudo das paisagens passadas. E acrescentaríamos esta dificuldade ao estudo da paisagem a partir de quaisquer outras disciplinas, das quais lançamos mão neste trabalho. Fica evidente então, que independente das visões tradicionais, a paisagem é uma mediação entre a natureza e a cultura, o que rechaça qualquer interpretação como exclusivamente natural ou cultural. Para Knapp e Ashmore (1999, p. 21, tradução nossa) as paisagens "são parte integrante do habitus de Bourdieu, as práticas sociais rotineiras dentro das quais as pessoas experimentam o mundo ao seu redor". Entretanto, além do habitus, ao habitar a paisagem as pessoas exercem atividades que ordenam, transformam, identificam e memorizam a paisagem, que só se manifesta como tal a partir da criação e experiência do espaço pelas pessoas, ou seja, da sua percepção como lugar. Este senso de lugar, assim como o envolvimento das pessoas com o mundo ao seu redor, possui uma relação de dependência das suas condições históricas (Knapp; Ashmore, 1999).

As referências paisagísticas variadas ora enfatizam a dimensão natural da paisagem através dos aspectos geomorfológicos, ecológicos, hidrológicos etc, ora enfatizam a dimensão cultural através dos aspectos tecnológico, organizacional, cosmológico etc. A superação da dualidade das duas abordagens, que afeta tanto arqueologia quanto outras ciências, ou seja, a paisagem como mediação entre cultura e natureza, se manifesta nas pesquisas, patrimonialização e gestão da Serra da Capivara?

\subsection{Aspectos teóricos e metodológicos nas pesquisas da Serra da Capivara}

Nos anos 1970 predominavam no Brasil duas filosofias de pesquisas arqueológicas implantadas por cientistas estrangeiros convidados por instituições locais para colaborarem na formação especializada: uma de influência americana com o Programa Nacional de Pesquisas Arqueológicas (Pronapa) e outra francesa através da Missão Franco-Brasileira. A última esteve presente no estado de Minas Gerais e na região nordeste.

A falta de profissionais para enfrentar a destruição do acervo arqueológico havia originado um movimento liderado por intelectuais ${ }^{3}$, que já conseguira em 1961 a instituição de legislação específica, mas ainda carecia de recursos humanos para sua aplicação. Então foram criados cursos e estágios de formação, destacando-se o projeto PRONAPA, realizado pela colaboração entre o IPHAN e a Smithsonian Institution, entre 1965 e 1971, que pretendia realizar prospecções e testes rápidos visando elaborar um quadro das culturas brasileiras. Participaram do projeto o museu paraense Emílio Goeldi e pesquisadores isolados do sul e do nordeste. Outras instituições brasileiras, como o Museu Nacional, Museu Paulista, Museu de Antropologia da UFSC e Instituto de Pré-História da USP, continuaram suas pesquisas baseadas em escavações sistemáticas de sítios, o que gerou uma divisão no Brasil e na América Latina entre a escola propagada pelo casal norte-americano Clifford Evans e Betty Jane Meggers e as outras escolas. Em 1970, a complementaridade das duas abordagens de pesquisas levou algumas equipes à tentativa de manter as prospecções paralelas às escavações sistemáticas, tais como o Instituto de Arqueologia Brasileira (IAB) e as universidades federais de Minas Gerais e do Piauí, esta última sob a coordenação da arqueóloga Niède Guidon (PROUS, 1992).

Além dos Evans, o casal formado pelo geógrafo Joseph Emperaire e pela arqueóloga Annette Laming tiveram papel importante

3 Destacam-se no movimento Paulo Duarte, político de São Paulo e criador da Comissão de Pré-História da USP, posteriormente Instituto de Pré-História, o antropólogo L. de Castro Faria, do Museu Nacional e José Loureiro Fernandes, da Universidade do Paraná. 
na formação dos arqueólogos brasileiros, nos anos 1960. O primeiro inspirando os trabalhos referentes à cerâmica e o segundo ao material lítico. E, na década de 1970, o interesse pela arte rupestre através de levantamentos sistemáticos com interpretação estruturalista apresentou convergência com as teorias de Annette Laming-Emperaire e de Leroi-Gourhan, sendo os da Missão Franco-Brasileira, realizados a partir de 1973, os mais complexos. A missão, formada por um grupo do Centre National de la Recherche Scentifique, se desdobrou em pesquisas em Minas Gerais, em convênio com o Museu Nacional e a Universidade Federal de Minas Gerais (UFMG) e, no Piauí, com o Museu Paulista e a Universidade Federal do Piauí (UFPI), ambos orientados por Annette Laming-Emperaire (PROUS, 1992).

A ideia de etnografia comparada, de Leroi-Gourhan, surge num contexto nutrido pela antropologia e pelo orientalismo, desencadeando uma abordagem etnológica aplicada à pré-história. Sua escola destaca o registro, a técnica da decapagem em escavações de amplas superfícies, as pesquisas das relações mais relevantes do que do objeto; trabalha com aportes etnológicos e antropológicos; identifica o tempo sincrônico, o espaço sociológico de determinado momento. Postula que a manutenção e reprodução de aspectos conservadores dos grupos sociais permitem sua identificação pelos tipos de artefatos, na sua funcionalidade e duração, impressos pela "cadeia operatória" em seus gestos técnicos, sem negligenciar o papel do meio ambiente nesta produção (MOHEM et al., 1990 apud REIS, 2004).

As pesquisas interdisciplinares desenvolvidas na Serra da Capivara, que estudam os paleoambientes e as mudanças da paisagem através da estratigrafia de diferentes tipos de sítios arqueológicos e paleontológicos, são essenciais para entender a interação do homem com a paisagem ao longo do tempo, consolidando a interdependência das pesquisas arqueológicas e paleoambientais (PESSIS; MARTIN; GUIDON, 2014).

Quanto a esta influência do ambiente sobre o homem, é inevitável associá-la à premissa do geógrafo francês Paul Vidal de La Blache, para quem "a história de um povo é inseparável da área em que ele habita" (RIBEIRO, 2010, p. 40). Ribeiro observa o papel não explícito e relevante da tradição vidalina, que conflui com a ecologia na construção da ideia de paisagem cultural da UNESCO, instituída em 1992. Influência percebida inclusive na justificativa de algumas inclusões na Lista do Patrimônio Mundial dentro desta categoria. Vidal de La Blache funda um conhecimento geográfico distanciado das relações de causa e efeito e sua obra é considerada fundadora da corrente de pensamento do "Possibilismo", em contraposição ao "Determinismo Geográfico" do geógrafo alemão Friedrich Ratzel.

A maior influência de Leroi-Gourhan no Brasil, entretanto, oriunda do estruturalismo, é na arte rupestre, que está também presente nos trabalhos de Annette Laming-Emperaire, com o contraste de hipóteses oriundas de análises estruturais da arte rupestre com informações etnográficas (REIS, 2004). Guidon, ao prefaciar o livro Imagens da Pré-História, de Anne-Marie Pessis, a destaca: "Seguindo a linha de reflexão iniciada por Leroi-Gourhan, Anne Marie Pessis vai mais além, refletindo sobre as dimensões etológicas da comunicação e a capacidade dos primatas de apreensão de imagens" (PESSIS, 2013, p. 12).

\section{Cultura Material e Paisagem nos Discursos da Patrimonialização}

Em meados do século $X X$, a natureza passa a ser percebida como frágil e seus recursos, necessários à vida humana, finitos. Tanto a natureza quanto os artefatos humanos devem ser doravante protegidos de acordo com os valores atribuídos por cada sociedade. A patrimonialização da natureza e dos bens culturais é contemplada pela UNESCO na Convenção do Patrimônio Mundial, de 1972. No Brasil, a constituição de 1988, em seu artigo 225, prescreve que o homem deve ter direito a um "meio ambiente ecologicamente equilibrado". Pelo artigo 215, o "Estado garantirá a todos o pleno exercício dos direitos culturais e acesso às fontes de cultura" e o artigo 216 define um conceito abrangente de patrimônio cultural. As narrativas para justificar a patrimonialização de uma extensa área no sudeste do Piauí, rica em atributos 
culturais pré-históricos e recursos naturais, encontram contexto favorável e respaldo legal.

A integração entre os três campos - patrimônio cultural, proteção do meio ambiente e arqueologia - no tratamento da paisagem da Serra da Capivara é o fio condutor para a compreensão das suas concepções e práticas. Levantamos os primeiros aspectos perceptíveis em cada um destes campos na patrimonialização desta paisagem, os quais reiteram ou afastam esta integração. Iniciamos pela identificação dos recursos e como eles são mobilizados no processo de proteção específico do Parna SC.

A arqueóloga, Niède Guidon, tendo iniciado suas incursões à Serra da Capivara no início dos anos 1970 e constatando a concentração extraordinária de testemunhos da presença antiga do homem na região, principalmente as pinturas rupestres, conseguiu financiamento e cooperação de outros cientistas junto ao Governo Francês para formar uma equipe dentro da Missão Franco-Brasileira, responsável pelos primeiros trabalhos de pesquisa. Segundo Borges e Santana (2015), nestas incursões de campo, foram constatadas as condições inóspitas para a preservação dos ecossistemas regionais, sobretudo decorrentes das atividades agrícolas e da caça. A ameaça crescente de destruição de registros rupestres levou Niède a protagonizar o pedido ao então governador do Piauí, Dirceu Arcoverde, para a criação do parque nacional na região.

A Serra da Capivara talvez seja o exemplo mais emblemático da articulação destas duas categorias de patrimônio inscrita no Livro do Tombo Arqueológico, Etnográfico e Paisagístico, em 1993, apesar das particularidades do seu registro neste livro. Uma inscrição tardia e imposta externamente e à posteriori, já que seu reconhecimento internacional como patrimônio cultural da humanidade - pelo seu rico acervo de inscrições rupestres - é anterior. O título internacional foi conquistado em 1991 porque, além de atender aos critérios ${ }^{4}$ estabelecidos pela Convenção do

4 O Comitê de assessoramento da UNESCO define os critérios para a inscrição

dos bens na Lista do Patrimônio Mundial. Estes são regularmente revistos pelo Comitê do Patrimônio Mundial a fim de refletirem a evolução do conceito de Patrimônio Mundial.
Patrimônio Mundial, de 1972, da Organização das Nações Unidas para a Educação, Ciência e Cultura (UNESCO), o Governo Brasileiro já tinha assegurado sua proteção com a criação do PARNA SC, uma unidade de conservação integral sob a responsabilidade do antigo Instituto Brasileiro de Desenvolvimento Florestal (IBDF), depois Instituto Brasileiro do Meio Ambiente (IBAMA) e, posteriormente, Instituto Chico Mendes de Preservação da Biodiversidade (ICMBIO). Trata-se de uma lista de patrimônios nacionais com interesse internacional, organizada e estruturada em torno dos Estados Nacionais, que indicam a candidatura e se responsabilizam posteriormente por sua gestão através de uma patrimonialização baseada em um discurso de construção da nação (RIBEIRO, 2010).

O tombamento é desvalorizado perante o título mundial e a proteção como parque nacional; ele é pouco citado nos documentos científicos e propagandas turísticas. Esta desvalorização gera interpretações confusas, como ocorreu dentro do próprio IPHAN, que chegou a divulgar no seu site na internet ser o PARNA SC um patrimônio mundial natural ao invés de cultural, como na verdade é reconhecido pela UNESCO.

A forma de proteção escolhida a priori pelos cientistas interdisciplinares, protagonistas na sua postulação ao Governo Brasileiro, efetivada em 1979 com a criação de uma unidade de conservação na forma de um parque nacional, no lugar do tombamento, sugere conclusões e aponta desdobramentos. Esta escolha poderia explicar ou, no mínimo, reforçar o quadro tão pouco representativo dos registros dos bens arqueológicos e da paisagem no livro criado para esse fim? Pouco uso se fez deste livro até a década de 1970. Em que medida a interação ou relação de dependência entre o bem arqueológico e a paisagem, em última análise, cultura e natureza, são determinantes na instituição de determinadas formas de proteção inseridas na política patrimonial e/ou ambiental brasileiras nas últimas décadas e virada do século $X X$ para o XXI, quando o país vivia um processo de redemocratização? Qual é a perspectiva desta relação entre natureza e cultura nestas duas políticas e como elas se articulam? Superposição, complementaridade ou interação? 
A fala abaixo pode iniciar as respostas buscadas e sugerir outras questões. Faz parte de um documentário produzido pela Representação da Unesco no Brasil e foi feita pela arqueóloga, Niède Guidon, coordenadora responsável pelas pesquisas arqueológicas e cogestão do Parna SC à frente da Fundação Museu do Homem Americano (Fumdham), que há 40 anos realiza pesquisas interdisciplinares na região sudeste do Piauí.

É o que nós estamos procurando desenvolver aqui, desde que o Banco Interamericano fez um estudo sobre a questão econômica da região, como fazer para obter o desenvolvimento econômico e social. Então, eles chamaram a atenção para o fato de que agricultura aqui nunca seria uma solução definitiva, porque o solo é muito raso, é salgado, cheio de pedras e temos secas muito grandes. Já passei aqui cinco anos sem chuva, não? Então, eles recomendaram que se investisse no turismo, porque nós temos um patrimônio arqueológico fantástico e temos uma paisagem que é belíssima (SERRA..., 2013, 31: 08 min.- 31: 40 min., grifo nosso).

No depoimento acima, a paisagem associada ao turismo é destacada primeiramente como uma realidade percebida empiricamente pelo sentido da visão, de uma maneira externa ao observador. Segundo Corbin (2001), de uma maneira distanciada e numa atitude espectável, uma vez submetida à primazia da visão, que já havia interrompido sua leitura polissensorial desde o Renascimento. Da percepção da paisagem, que a traduz em espaço percebido por um "golpe de vista" (CORRÊA, 2013, p. 58), decorrem seus sinônimos mais usuais, baseados no senso comum: cena, panorama e imagem. Esta forma de percepção apena sugere a complexidade das suas variadas abordagens, que podem ser extraídas na instituição da Serra da Capivara como patrimônio.

Em 1986, os pesquisadores da antiga Missão Franco-Brasileira criaram a organização não governamental Fumdham, que tem desde então atuado na pesquisa, proteção e gestão do patrimônio do Parna SC. A Fumdham elaborou, em 1990, uma proposta de plano de manejo. Este plano, embora tenha sido usado como base de informações para os dossiês que postulam tanto o título patrimônio cultural mundial quanto o nacional, jamais foi acatado e assumido oficialmente pelo órgão do meio ambiente. O Parna SC só teve este instrumento de gestão aprovado recentemente, em julho de 2019, o que se conclui por consulta ao site do ICMbio.

De acordo com o Plano de Manejo de 1990 (INSTITUTO..., 1992a), os atributos da área que suscitaram a criação do Parna SC são ordenados segundo três categorias: ambientais, culturais e turísticas. Na primeira figura a preservação das paisagens variadas - serras, vales e planície - das duas formações geológicas fronteiriças e do bioma caatinga. A categoria seguinte destaca a concentração de sítios arqueológicos, com predomínio das pinturas e gravuras rupestres e vestígios da presença humana com datações muito antigas, numa riqueza e variedade de manifestações: sítios ao ar livre (acampamento e aldeias) de caçador-coletores, aldeias de ceramistas agricultores, ocupações em grutas ou abrigos, sítios funerários etc. Na terceira categoria aparecem as "[...] paisagens de uma beleza surpreendente, com pontos de observação privilegiados [...]" (INSTITUTO..., 1992a, p. 24), consideradas como recursos para um turismo ecológico e cultural, com destaque à contemplação, proposto desde a concepção do parque (Figura 2).

No dossiê submetido ao Comitê do Patrimônio Mundial da Unesco, preparado pelo Ibama e a Fumdham, a paisagem também aparece como justificativa para o título de patrimônio mundial em dois dos critérios postulados como valores naturais:

iii- representar fenômenos naturais notáveis ou áreas de beleza natural e de importância estética excepcionais. Contém belas paisagens exibindo formações rochosas únicas esculpidas pela erosão da chuva para formar caldeirões, boqueirões, pingas e falésias de cuestas.

iv- conter os habitats naturais mais representativos e mais importantes para a conservação in situ da diversidade 


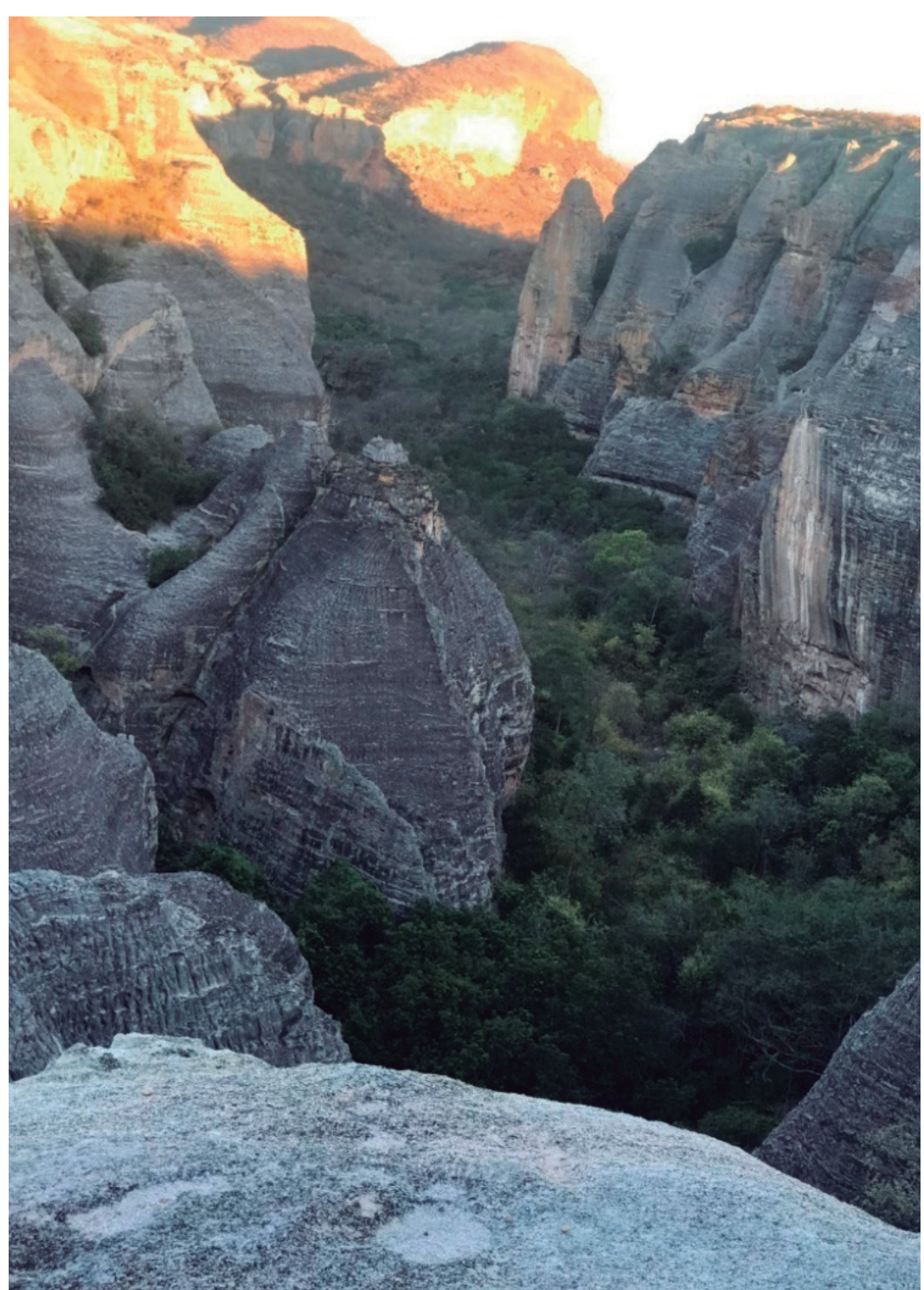

Figura 2: Vista do Baixão das Andorinhas no Parna SC, em São Raimundo Nonato, ao final da tarde, a partir de ponto de observação destinado à contemplação da paisagem. biológica, nomeadamente aqueles em que sobrevivem espécies ameaçadas que tenham um Valor Universal Excepcional do ponto de vista da ciência ou da conservação. Serra da Capivara é reconhecida como uma das poucas áreas protegidas dentro da província biogeográfica da caatinga, que inclui um tipo de vegetação endêmica no nordeste do Brasil. Constam espécies únicas de animais desconhecidos em outros lugares (INSTITUTO..., 1992c, p. 95, tradução nossa).

Contudo, a avaliação técnica da União Nacional para a Conservação da Natureza (IUCN) ${ }^{5}$ não acata a justificativa baseada em valores naturais apresentada pelo Governo Brasileiro para a designação do PARNA SC como patrimônio mundial. Observa que há poucas informações sobre estes valores e seu manejo e os considera secundários em relação aos valores culturais, apontando a análise sobre estes últimos, do Conselho Internacional de Monumentos e Sítios (Icomos), mais decisiva (INSTITUTO... c, 1992, p. 98). E assim a recomendação final do ICOMOS indica a inscrição fundamentada no critério "iii- constituir um testemunho único ou pelo menos excepcional de uma tradição cultural ou de uma civilização viva ou desaparecida" (UNITED..., 2008):

Os abrigos no Parque Nacional da Serra da Capivara são testemunhos excepcionais das mais antigas comunidades humanas que povoaram a América do Sul e preservam os exemplos mais antigos de arte rupestre no continente. Além disso, a decifração da iconografia dessas pinturas rupestres, que está sendo realizada gradualmente, revela aspectos importantes das crenças e práticas religiosas desses povos (INSTITUTO..., 1992c, p. 90, tradução nossa).

As figuras 3 e 4 mostram alguns dos testemunhos excepcionais contemplados pelo critério iii. Até a década de 1980, este critério referia-se às propriedades que eram consideradas "um testemunho único ou pelo menos excepcional de uma civilização que desapareceu" (UNITED..., 1980). Era restrito a sítios arqueológicos

5 A IUCN e o Conselho Internacional de Monumentos e Sítios (ICOMOS) são organizações consultivas do Comitê do Patrimônio Mundial, que estabelecem critérios para inclusão dos bens na Lista do Patrimônio Mundial. 
raros e de grande antiguidade. Na década de 1990 passa a ter a definição que contempla as civilizações e tradições vivas, além das desaparecidas, com destaque aos bens imateriais e a incorporação das paisagens culturais continuadas. $O$ enquadramento neste critério exige do bem a excepcionalidade da antiguidade e da raridade de uma tradição desaparecida, caso da Serra da Capivara. Ou da tradição viva, a exemplo da paisagem cultural Sukur, na Nigéria, inscrita depois, em 1999, que mantém a tradição do uso da terra de forma particular através de séculos.

O parecer jurídico da Procuradoria Federal do Iphan quanto à aplicação do tombamento ao Parna SC (INSTITUTO..., 1992b), homologado em 1993, sustenta uma posição dual. No parecer elaborado antes da candidatura ser submetida à decisão do Conselho Consultivo do Patrimônio Cultural ${ }^{6}$, recomenda que este recaia preferencialmente sobre as áreas públicas do Parna SC, mas pelos seus valores paisagísticos e não por seus valores arqueológicos. Justifica este posicionamento por considerar a Lei $\mathrm{n}^{\circ}$ 3924/1961 mais adequada à proteção de sítios arqueológicos, que necessitam de intervenções mais profundas decorrentes do método de pesquisa, mudando a feição dos locais. Por isto, eles não atendem às regras de preservação previstas pelo Decreto-lei $n^{\circ}$ 25/1937. Assim, considera o tombamento para a paisagem circundante aos sítios arqueológicos e a proteção da Lei n 3924/1961 para estes, desconhecendo toda a riqueza das inscrições rupestres da região, principal atributo cultural que motivou o seu reconhecimento mundial.

Depreende-se do contexto da proteção do Parna SC a importância da percepção visual na fruição da paisagem, usada também como forma de convencimento/sedução para a proteção da área (Figura 5). Os objetos selecionados para constituírem o patrimônio, segundo Gonçalves (1996), são submetidos às ações de preservação com o objetivo de exibição e contemplação, numa forma de conceber o conhecimento autenticado pela exibição como representação visual.

6 Conselho constituído por nove representantes de instituições públicas e privadas e treze representantes da sociedade civil, indicados pela presidência do IPHAN.

\section{Considerações Finals}

Ao examinarmos as circunstâncias da patrimonialização da Serra da Capivara no contexto da política ambiental, numa época em que o Brasil ainda vivia sob o regime da ditadura militar, constata-se uma imposição de modelos. A criação do Parna SC, em 1979, como unidade de proteção integral da natureza, é entendida pela "manutenção dos ecossistemas livres de alterações causadas por interferência humana, admitido apenas o uso indireto dos seus atributos naturais" (BRASIL, 2011, p. 5, grifo nosso). A Lei $n^{\circ} 9.985$, de 18 de julho de 2000, ao regulamentar o artigo 225 da Constituição Federal e instituir o Sistema Nacional de Unidades de Conservação da Natureza (Snuc), prescreve no seu artigo 11:

O Parque Nacional tem como objetivo básico a preservação de ecossistemas naturais de grande relevância ecológica e beleza cênica, possibilitando a realização de pesquisas científicas e o desenvolvimento de atividades de educação e interpretação ambiental, de recreação em contato com a natureza e de turismo ecológico (BRASIL, 2011, p. 10).

Ele tem por "objetivo básico preservar a natureza, sendo admitido apenas o uso indireto dos seus recursos naturais [...]" (BRASIL, 2011 , p. 9, grifo nosso), e pressupondo a propriedade do seu território pela União ${ }^{7}$. Denota assim uma perspectiva da natureza separada do homem que exclui o homem do presente e afasta as comunidades tradicionais, como foi o caso da comunidade Zabelề . Fruto da preocupação com a ecologia e a proteção do meio ambiente, não admite a interferência humana, mas a inserção do homem do passado na paisagem, através da proteção dos vestígios da sua cultura material.

Em 1991, o reconhecimento do Parna SC pela Unesco ainda tra-

7 Ver parágrafos $1^{\circ}, 2^{\circ}$ e $3^{\circ}$ do artigo 11 da Lei no 9985/2000 (BRASIL, 2011, p.10).

8 Comunidade removida do Parna SC e submetida a indenizações precárias. A

posse da terra pelos membros da comunidade tem origem na ocupação decorrente da procura da maniçoba nativa para a fabricação de borracha entre o final do século XIX e o começo do XX. 

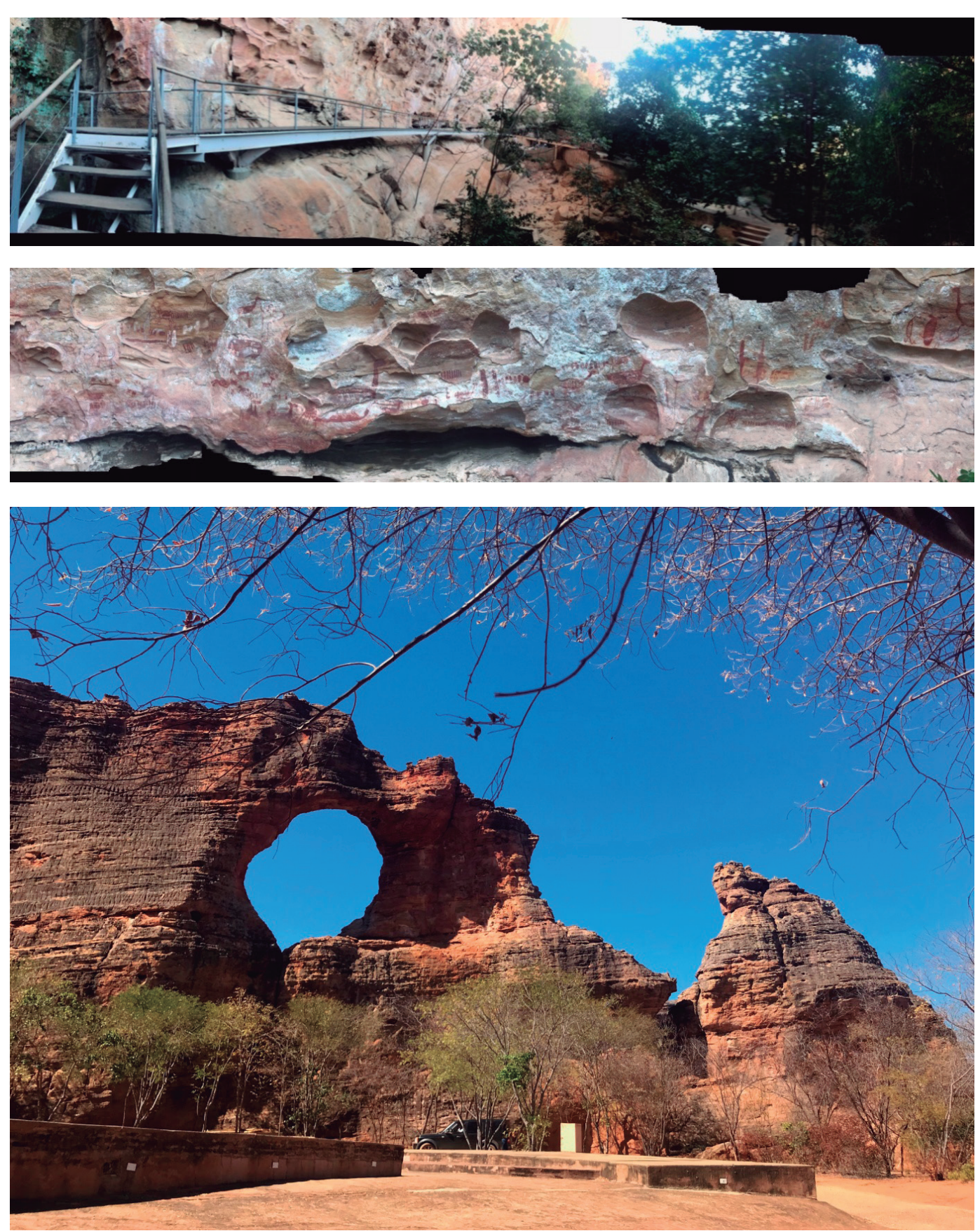

Figura 3: Vista panorâmica do sítio Boqueirão da Pedra Furada, no Parna SC, mostrando o paredão contínuo com diversidade de pinturas rupestres e parte da escavação arqueológica onde foram encontrados registros de ocupação humana de vários períodos e os vestígios mais antigos da ocupação humana no continente americano.

Figura 4: Vista panorâmica dos painéis com pinturas antropomorfas e zoomorfas do Boqueirão da Pedra Furada, que retratam cenas de vida de civilizações desaparecidas.
Figura 5 - Vista da Pedra Furada, um dos cartões postais do Parna SC, que se torna pano de fundo de um palco ao ar livre destinado a eventos culturais. 
balhou com a abordagem dicotômica entre cultura e natureza, cujos valores são avaliados por organismos diferentes, lucn e Icomos. A noção de paisagem integrada aos bens culturais e naturais e o seu emprego por diversas disciplinas resultará na adoção, em 1992, da categoria de proteção de paisagem cultural na Convenção do Patrimônio Mundial (RIBEIRO, 2010). O tombamento, da mesma forma, lança mão de fundamentos legais distintos para proteção ora do patrimônio arqueológico pela Lei $n^{\circ} 3921$, de 1962, ora da paisagem natural circundante pelo Decreto-lei $\mathrm{n}^{\circ} 25$, de 1937.

A preservação da Serra da Capivara certamente foi uma entre tantas que desafiaram a forma ambivalente como o Brasil e a própria Unesco tratavam a relação cultura e natureza, apesar da ampliação e difusão do conceito de patrimônio nos anos 1960. A forma estanque de tratar os patrimônios cultural e natural por organismos distintos, demarcando suas respectivas áreas e com reduzidos esforços na sua conexão, ainda persiste no cenário brasileiro. Algumas tênues aproximações entre os dois patrimônios foram provocadas principalmente pelos patrimônios arqueológico e imaterial no contexto do licenciamento ambiental. Houve um esforço maior do Iphan ao instituir a chancela da paisagem cultural, em 2009, considerada a categoria perfeita para a integração entre o patrimônio material e o imaterial, a natureza e a cultura. Esta nova categoria de patrimônio é definida como "uma porção peculiar do território nacional, representativa do processo de interação do homem com o meio natural, à qual a vida e a ciência humana imprimiram marcas ou atribuíram valores" (INSTITUTO..., 2009, p.35). Entretanto, a paisagem cultural como categoria patrimonial continua a impor grandes desafios, pois é dependente da participação e conciliação dos interesses de inúmeros atores.

Por seu lado, a Convenção do Patrimônio Mundial continuou por longo tempo, classificando estes dois patrimônios separadamente. No caso específico do Parna SC, ao considerar apenas critérios culturais para sua inscrição na Lista do Patrimônio Mundial, apesar da indicação brasileira como patrimônio misto, diminuiu a importância da forte imbricação dos vestígios da cultural ma- terial de comunidades humanas pretéritas com o seu meio, relegando-o a segundo plano. Em 1992, ano seguinte à inscrição do Parna SC na Lista do Patrimônio Mundial, acrescenta-se a paisagem cultural como categoria de inscrição na lista, definindo-a como representante do "trabalho combinado da natureza e do homem... sob a influência de determinantes físicas e/ou oportunidades apresentadas por seu ambiente natural e das sucessivas forças sociais, econômicas e culturais, tanto internas, quanto externas" (UNITED..., 1992).

Entretanto, até 2005, os bens candidatos ao título ainda são selecionados com base em seis critérios culturais e quatro naturais, separadamente. A partir daí são reunidos em dez critérios sem distinção como forma de quebrar a sua prolongada dicotomia, indicativo da dificuldade de assimilação das mudanças operadas em 1992 pelo próprio Comitê do Patrimônio Mundial, presidido pelo eurocentrismo.

Cauquelin (2007) observa o desempenho importante da paisagem para a encenação dos elementos naturais - água, terra, fogo e ar -, que separadamente são invisíveis e são retomados e assumidos no conjunto pela arte de enquadrar e compor. Seu significado ultrapassa em muito o rótulo estético ao assegurar "os quadros de uma percepção comum" (CAUQUELIN, 2007, p. 10) e unir em uma só visão os diversos setores da política ambiental.

Corbin (2001) nota que os geógrafos evocavam a paisagem para descrevê-la pelo mais evidente, que se impôs com a morfologia e a ecologia. Assim, uma ciência objetiva e a noção de paisagem definida por sua materialidade dominaram por longo tempo até a complexa intervenção dos filósofos, sociólogos e antropólogos. Resumidamente, pode-se concluir como um dos resultados desta intervenção que "paisagem é uma maneira de experimentar e apreciar o espaço" (CORBIN, 2001, p. 9, tradução nossa). Entretanto, o autor observa que sua leitura é variável de acordo com indivíduos e grupos. A maneira de olhar está em contínua transformação desde a Renascença e sua historicidade deve ser relevada:

A noção de panorama, como a mecânica do olhar que 
determina a admiração despertada pelo jardim inglês, pertence à história. Mas a paisagem não se reduz a um espetáculo. O toque, o odor, especialmente a audição, também são importantes para a apreensão do espaço. Todos os sentidos contribuem para construir as emoções que ela proporciona (CORBIN, 2001, p. 9, tradução nossa).

O termo paisagem é extremamente polissêmico; ele é apropriado de maneiras diferentes pela arte e diversos campos do saber. A paisagem foi uma categoria usada como argumento decisivo no discurso da patrimonialização da Serra pelos cientistas e agentes técnicos da preservação do meio ambiente e do patrimônio cultural. Conhecer os significados que Ihe foram atribuídos nas narrativas patrimoniais brasileiras desde a instituição da preservação do patrimônio e, particularmente, as narrativas que foram selecionadas para legitimar a instituição da proteção e as práticas de gestão da Serra da Capivara, segue como um dos objetivos dessa pesquisa. Não menos importante é destacar o que muda com a patrimonialização: conhecer as variadas percepções locais e nacionais da imagem da região decorrentes da sua instituição como patrimônio.

\section{REFERÊNCIAS BIBLIOGRÁfICAS}

BAIÃO FILHO, Luiz Gonzaga. Parque Nacional Serra da Capivara e Gestação Interdisciplinar das Narrativas do Patrimônio Cultural. Clio, Recife, n. 31.1, p. 1-15, 2013. Dis ponível em: https://periodicos.ufpe.br/revistas/revistaclio/article/download/24426/19765. Acesso em: 18 mai. 2018.

BORGES, Jóina Freitas; SANTANA, Jaime de. Sociedade, Arqueologia e Patrimônio: As relações de pertencimento da Comunidade Zabelê com a área arqueológica do Parque Nacional Serra da Capivara (PNSC). História Unicap, v. 2, n. 3, p.108-121, 2015. Disponível em: http://www.unicap.br/ojs/index.php/historia/article/view/579/504. Acesso em: 17 mai. 2018. https://doi.org/10.25247/hu.2015.v2n3.pp.\%20108-121

BRASIL. Ministério da Cultura. Decreto-lei 25 de 30 de novembro de 1937. Organiza a proteção do patrimônio histórico e artístico nacional. Brasília, DF: Iphan, 1937. Disponível em: http://portal.iphan.gov.br/uploads/legislacao/Decreto_no_25_de_30_de_novembro_de_1937.pdf. Acesso em: 18 mai. 2018.

BRASIL. Ministério da Cultura. Lei 3924, de 26 de julho de 1961. Dispõe sobre os monumentos arqueológicos e pré-históricos. Brasília, DF: Iphan, 1961. Disponível em: http:// portal.iphan.gov.br/uploads/legislacao/Lei_3924_de_26_de_julho_de_1961.pdf. Acesso em: 18 mai. 2018

BRASIL. Ministério do Meio Ambiente. SNUC - Sistema Nacional de Unidades de Con- servação da Natureza. Brasília, DF: MMA/SBF, 2011. Disponível em: http://www.mma. gov.br/images/arquivos/areas_protegidas/snuc/Livro\%20SNUC\%20PNAP.pdf. Acesso em: 21 mai. 2018.

CAUQUELIN, Anne. A invenção da paisagem. Tradução de Marcos Marcionilo. São Paulo: Martins Fontes, 2007. (Coleção Todas as Artes). 196 p.

CONVENC̃̃O EUROPEIA DA PAISAGEM - CEP. Feita em Florença em 20 de Outubro de 2000. In Decreto n. ${ }^{\circ}$ 4/2005. Portugal, Gabinete de Documentação e Direito Comparado, 2005. Disponível em: file:///C:/Users/Diva/Downloads/Convenc\%CC\%A7a\% CC\%830\%20 Europeia\%20da\%20Paisagem\%20-\%202000-convencao_europeia_da_paisagem-conselho_da_europa.pdf\%20(3).pdf. Acesso em: 25 dez. 2019.

CORBIN, Alain. L'homme dans le paysage. Paris: Les éditions Textuel, 2001.

CORRÊA, Dora Shellard. História ambiental e a paisagem. HALAC, vol. 2, n. 1, p. 47-69, 2013. Belo Horizonte,. Disponível em: http://www.halacsolcha.org/index.php/halac/article/ download/187/182/. Acesso em: 05 abr. 2019.

FREIRE, Neison C. F. et al. Mapeamento e Análise Espectro-Temporal das Unidades de Conservação de Proteção Integral da Administração Federal do Bioma Caatinga: de Conservação de Proteção Integral da Administração Federal do Bioma Caatinga: Joaquim Nabuco, 2017. Disponível em: https://www.fundaj.gov.br/images/stories/cieg/ Joaquim Nabuco, 2017. Disponível em: https://www.fundaj.gov.br/images/stories/cieg/
atlas_caatinga/compressed_cap8parnaperuacucaatingafundaj.compressed-min.pdf. Acesso em: 20 mai. 2018.

GONÇALVES, José Reginaldo dos Santos. A retórica da perda: os discursos do patrimônio cultural no Brasil. Rio de Janeiro: Editora UFRJ; Iphan, 1996.

INSTITUTO DO PATRIMÔNIO HISTÓRICO E ARTÍSTICO NACIONAL-IPHAN. Paisagem Cultural. Brasília, DF: Depam, 2009. Disponível em: http://portal.iphan.gov.br/uploads/ckfinder/ arquivos/Livreto_paisagem_cultural.pdf. Acesso em: 10 jun. 2019

INSTITUTO DO PATRIMÔNIO HISTÓRICO E ARTÍSTICO NACIONAL - IPHAN. Processo de Tombamento da Serra da Capivara. v.1. Arquivo Central IPHAN, Seção Rio de Janeiro, 1992. Processo de Tombamento $n^{\circ} 1.322$ - T- 92. Documentação abrangendo o período de 1990-1993. 1992a.

INSTITUTO DO PATRIMÔNIO HISTÓRICO E ARTí́STICO NACIONAL - IPHAN. Processo de Tombamento da Serra da Capivara. v. 2. Arquivo Central IPHAN, Seção Rio de Janeiro, 1992. Processo de Tombamento $n^{\circ} 1.322$ - T- 92. Documentação abrangendo o período de 1990-1993. 1992b.

INSTITUTO DO PATRIMÔNIO HISTÓRICO E ARTÍSTICO NACIONAL - IPHAN. Processo de Tombamento da Serra da Capivara. Anexo 1. Arquivo Central IPHAN, Seção Rio de Janeiro, 1992. Processo de Tombamento $n^{\circ} 1.322$ - T- 92. Documentação abrangendo o período de 1990-1993. 1992c.

KNAPP, Bernard; ASHMORE, Wendy. Archaeological landscapes: constructed, conceptualized, ideational. In ASHMORE, Wendy; KNAPP, Bernard. Archaeologies of Landscape: contemporary perspectives. Massachussets and Oxford: Blackwell, 1999, p. 1-30. Disponível em: https://www.academia.edu/5271922/Archaeological_Landscapes_Constructed_Conceptualized_Ideational_A._Bernard_Knapp_and_Wendy_Ashmore_1999_. Acesso em: 24 jan. 2019.

LINO, Jaisson Teixeira. A arqueologia da paisagem como enfoque teórico para o estudo arqueológico da guerra do Contestado. Revista Tempos Acadêmicos, Criciúma, n. 10, p 58-67, 2012. Disponível em: http://periodicos.unesc.net/historia/article/download/1110/1069. Acesso em: 23 fev. 2019.

MEYER, Mônica. Ser-tão-natureza: a natureza em Guimarães Rosa. Belo Horizonte: Editora UFMG, 2008. 
PESSIS, Anne Marie. Imagens da Pré-História. 2 ed. São Raimundo Nonato: Fumdham, 2013. PESSIS, Anne Marie; MARTIM, Gabriela; GUIDON, Niède. Tema1- Ambiente e paleoambiente na região do Parque Nacional. In: Anne Marie Pessis, Gabriela Martim, Niède Guidon (orgs.) Os Biomas e as sociedades humanas na pré-história da região do Parque Nacional Serra da Capivara. v. 2 A. São Paulo: A\&A Comunicação, 2014. p. 55-56. PROUS, André. Arqueologia brasileira. Brasília, DF: Editora Universidade de Brasília, 1992. REIS, José Alberione dos. Não Pensa muito que dói: um palimpsesto sobre a teoria na arqueologia brasileira. Tese (Doutorado em História) - Universidade Estadual de Campinas. Campinas, 2004. Disponível em: http://repositorio.unicamp.br/jspui/handle/ REPOSIP/280834. Acesso em: 10 mar. 2019.

RIBEIRO, Rafael Winter. Paisagem cultural e patrimônio. Rio de Janeiro: Iphan: Copedoc, 2007. Disponível em: http://portal.iphan.gov.br/uploads/publicacao/SerPesDoc1_Paisagem Cultural_m.pdf. Acesso em: 17 jul 2018.

RIBEIRO, Rafael Winter. Um conceito, várias visões: paisagem cultural e a UNESCO. In: CATRIOTA, Leonardo Barci; MONGELLI, Mônica Medeiros (org.). COLÓQUIO IBERO-AMERICANO PAISAGEM CULTURAL, PATRIMÔNIO E PROJETO.1., 2010, Belo Horizonte. Anais [ ...] n.6, v. 1. Brasília, DF: Iphan; Belo Horizonte, MG: IEDS, 2017, p. 29-50. DisAnais $[\ldots]$ n.6, v. 1. Brasília, DF: Iphan; Belo Horizonte, MG: IEDS, 2017, p. 29-50. Dis-
ponível em: http://portal.iphan.gov.br/uploads/publicacao/anaispaisagemculturalweb_2. ponivel em: http://portal.ipho em: 18 jul. 2019 .

pdf. Acesso em: 18 jul. 2019. SERRA da Capivara. Direção: Edson Fogaça. Produção: Renan Montenegro. Produção executiva: Rodoferrô. Direção de fotografia: Patricia Sardá. Roteiro: Edson Fogaça. Tri lha sonora: Hamilton Pinheiro. IS min. Disponível em: https://www.youtube.com/watch?v=9576H-X39J8\&feature=youtu. be. Acesso em: 16 mai. 2018.

UNITED NATIONS, EDUCATIONAL, SCIENTIFIC AND CULTURAL ORGANIZATION-UNESCO Operational Guidelines for the implementation of the World Heritage Convention. Paris: World Heritage Centre, 1980. Disponível em: http://whc.unesco.org/archive/opguide80. pdf. Acesso em: 15 jun. 2018

UNITED NATIONS, EDUCATIONAL, SCIENTIFIC AND CULTURAL ORGANIZATION-UNESCO Cultural Landscape, History and Terminology. Paris: World Heritage Centre, 1992. Disponível em: https://whc.unesco.org/en/culturallandscape/\#1. Acesso em: 15 jun. 2018.

UNITED NATIONS, EDUCATIONAL, SCIENTIFIC AND CULTURAL ORGANIZATION-UNESCO. Operational Guidelines for the implementation of the World Heritage Convention. Paris: World Heritage Centre, 2008. Disponível em: https://whc.unesco.org/archive/opguide08-en. pdf\#annex1. Acesso em: 15 jun. 2018
Diva Maria Freire Figueiredo

Universidade Federal de Minas Gerais. Programa de Pós-Graduação em Ambiente Construído e patrimônio Sustentável.

Rua Dr. Sales, 312, Boa Esperança, MG, Brasil, CEP: 37170-000.

ORCID: https://orcid.org/0000-0003-2000-3586

divamff@gmail.com

\section{Myriam Bahia Lopes}

Universidade Federal de Minas Gerais. Programa de Pós-Graduação em Ambiente Construído e patrimônio Sustentável.

Rua Paraíba, 697, sala 411. Belo Horizonte, MG, Brasil, CEP: 30130- 140.

ORCID: https://orcid.org/0000-0003-4146-4058

bahialopesmyriam@mac.com

Nota do Editor

Revisão do Texto: Tikinet; Marina Viscarra

Submetido em: 16/08/2019

Aprovado em: 13/11/2019 